\title{
REPRESENTAÇÃO DE UMA CULTURA MARGINAL EM “SOMBRAS”, DE SÉRGIO SANT'ANNA
}

\section{Acácio Luiz Santos ${ }^{1}$}

\begin{abstract}
Resumo: Este artigo investiga a representação de uma cultura marginal em "Sombras", de Sérgio Sant'Anna, enfatizando o fracasso ético, o eto discursivo e os modos e aspectos narrativos.

Palavras-Chave: Sérgio Sant'Anna, Literatura pós-moderna, Eto discursivo, M odos e aspectos narrativos.
\end{abstract}

\begin{abstract}
This article investigates the representation of a marginal culture in Sérgio Sant'Anna's story "Sombras", emphasizing ethical failure, the discursive ethos, and narrative moods and aspects.

Key Words: Sérgio Sant'Anna, Postmodern literature, Discursive ethos, Narrative moods and aspects.
\end{abstract}

\section{INTRODUÇ̃̃O}

O objetivo do presente artigo é uma leitura do conto "Sombras", de Sérgio Sant'Anna, publicado originalmente no volume de contos Notas de Manfredo Rangel, repórter (a respeito de Kramer), em 1973. Mais especificamente, pretendo destacar a representação de uma cultura marginal no conto, enfatizando os problemas éticos decorrentes. Antes de proceder à leitura, no entanto, torna-se necessário que se estabeleçam algumas definições preliminares. Inicialmente, é importante considerar o conceito de cultura marginal. Entendo para a presente exposição "cultura" como "o conjunto dos modos de vida de um grupo humano determinado, sem referência ao sistema de valores para os quais estão orientados esses modos de vida" (ABBAGNANO, 2000, p. 229). A cultura, neste sentido, como modo, distingue-se de civilização enquanto organismo, e de sociedade enquanto sistema. Desta forma, nada impede que uma dada civilização, com seus vários sistemas, possua uma pluralidade de grupos, possuidores de vários modos de vida. Ocorre somente que, entre estes vários modos de vida (ou, propriamente, culturas), alguns (poucos) orientam de modo especial as significações gerais da civilização em que se inserem, formando um paradigma civilizacional, sempre dinâmico e sujeito a mudanças no decorrer da história. Por sua vez, a cultura, historicamente considerada, envolve sempre uma problemática decorrente de sua identidade ou afastamento em relação aos sustentáculos significativos da civilização em que ela se insere (ou civilização inserente). No caso particular da contemporaneidade, o problema

1 Doutor em Literatura Comparada, pela Universidade Federal Fluminense - UFF; professor do Departamento de Letras Clássicas e Vernáculas, Instituto de Letras da UFF, em Niterói, Rio de Janeiro. Endereço eletrônico: santosacacioluiz@yahoo.com.br. 
fundamental de suas culturas "é sempre o mesmo: conciliar as exigências da especialização (inseparáveis do desenvolvimento maduro das atividades culturais) com a exigência de formação humana, total ou, pelo menos, suficientemente equilibrada" (ABBAGNANO, 2000, p. 227). Por conseguinte, entendo "cultura marginal", neste trabalho, como cultura "diferente dos" ou "oposta aos" paradigmas dominantes da civilização. No caso do conto em questão, centrado em torno de um personagem periférico ao modo de vida sócio-éticoeconômico paradigmático, a narrativa representará também a falência de seu ser como pessoa ética. Torna-se importante, aqui, relembrar o conceito fundamental de "etica" como "ciência da conduta", considerada "como ciência do fim para o qual a conduta dos homens deve ser orientada e dos meios para atingir tal fim, deduzindo tanto o fim quanto os meios da natureza do homem" (ABBAGNANO, 2000, p. 380), em que o fim é identificado a um bem. A obtenção deste bem, na relação de intersubjetividade, conduz o eto (ou ethos) discursivo do sujeito, sendo este eto marcado por um conjunto de princípios mínimos. Inicialmente, ele "é uma noção discursiva, ele se constrói através do discurso, não é uma "imagem" do locutor exterior a sua fala". Em segundo lugar, ele "é fundamentalmente um processo interativo de influência sobre 0 outro". E, em terceiro lugar, ele "é uma noção fundamentalmente híbrida (sócio-discursiva), um comportamento socialmente avaliado, que não pode ser apreendido fora de uma situação de comunicação precisa, integrada ela mesma numa determinada conjuntura sócio-histórica" (M AINGUENEAU, 2008, p. 17). Na narrativa, por sua vez, a representação do eto discursivo está relacionada visceralmente às estruturas que asseguram o funcionamento semiótico narrativo, e que, conforme o modelo greimasiano, podem ser modais e aspectuais. Quanto às primeiras, elas se compartimentam conforme as qualidades atribuídas aos actantes ou conforme o resultado de suas ações. Destarte, as "modalidades do "querer" e do "dever" pertencem ao nível virtual dos valores, as modalidades do "poder" e do "saber" pertencem ao nível da atualidade, e as modalidades do "fazer" e do "ser" pertencem ao nível da realização" (NÖTH, 2005, p. 161). Quanto às estruturas aspectuais, elas "descrevem continuidades, descontinuidades, estabilidades e instabilidades na representação narrativa dos eventos" (NÖTH, 2005, p. 162). A narrativa, no entanto, representa uma encenação de informação, que prevê a necessidade intrínseca de um sujeito informante. Este, por seu turno, diante dos componentes da situação de comunicação, "pode jogar com tais componentes, combiná-los de uma maneira particular e apresentá-los de diversas formas" (CHARAUDEAU, 2007, p. 129). Quanto às dimensões que significam o personagem, configurando a lógica do discurso, elas relacionam-se a três noções: "(1) a transformação su- 
jeita a um programa de ação; (2) 0 acontecimento que afeta passionalmente a posição da instância de discurso; e (3) a apreensão e a descoberta da mudança, consideradas como fonte de conhecimento" (FONTANILLE, 2007, p. 189). Desta forma, a narrativa constrói a verossimilhança a partir da tridimensionalidade representada. Munido de tais definições, chega entretanto o momento de proceder à leitura proposta de "Sombras".

\section{UMa CULTURA M arginal RePRESENTADA}

O conto "Sombras", de Sérgio Sant'Anna, inicia-se com a escalada do personagem central, um morador de morro, rumo a casa:

O homem vinha subindo o morro, quando já estava quase anoitecendo. As luzes
se acendiam, aos poucos. As luzes estavam mais fracas hoje. Um defeito habitual
na eletricidade lá em cima. Mas hoje as luzes da cidade inteira estavam mais fra-
cas. O homem parava para tomar fôlego e olhava a cidade lá embaixo. As luzes
enfraquecidas da cidade. O homem morava numa das casas mais altas: do outro
lado era o precipício (SANT'ANNA, 1977, p. 59).

A partir do trecho acima, é possível observar o trabalho metonímico e a economia da narrativa: a simples referência espacial produz uma informação indicadora da condição social inferior do personagem, desde que remetida ao contexto sócio-cultural (especialmente no Rio de Janeiro, onde a ocupação e, depois, a invasão sistemática de morros, alguns extremamente íngremes, vem ocorrendo há décadas). Portanto, a significação do texto prevê uma relação com um contexto extrínseco à narrativa, o que indica, semioticamente, a construção de um signo sobreposto, do texto narrativo e do texto como referência a uma realidade socialmente vivenciada, participante ativo, portanto, da semiosfera em que se insere. No âmbito mais restrito, o do texto, o personagem mora em um local de difícil acesso, que o leva a parar "para tomar fôlego"; além disso, sua casa, além de situar-se num ponto bem alto do morro, fica à beira do precipício, indicando uma moradia não escolhida por livre vontade, mas por carência. 0 plano espacial do homem, pois, caracteriza-se como desconfortável e perigoso, anunciando uma ameça potencial à afirmação do ser. Esta ameaça, no plano actancial, é de resto confirmada no parágrafo seguinte:

0 homem vinha subindo e observando bem o caminho, para não tropeçar. Porque estava ficando escuro. Mas o homem via umas pedras no chão e chutava as menores, com raiva. 0 homem tinha raiva de subir aquilo tudo e estava cansado. Ele chutava as pedrinhas, suando (SANT'ANNA, 1977, p. 59).

A primeira ação representada referente a um acontecimento que afeta passionalmente 0 personagem significa, portanto, raiva, que 0 homem descompensa chutando pedrinhas com força. Conforme o que foi dito na introdu- 
ção sobre a definição de ética, esta é uma ciência da conduta em vista de um fim identificado a um bem. A conduta descompensatória do personagem, no entanto, ao visar às pedras como fim de emergência, denota uma visão de bem último lacunar. Em outras palavras, o personagem abdica de procurar um bem, o que provoca, em conseqüência, uma ruptura na referência temporal: em vez de significar seu presente por meio de uma rememoração das experiências do passado e conseqüente escolha de valores (e, portanto do[s] bem[ns] desejável[-is]), que orientarão sua conduta futura, o homem sem escolha de um bem como fim de sua conduta reprojeta sua frustração experiencial ao sabor das circunstâncias fortuitas, como no caso das pedrinhas, para descompensar o peso do não-ser (no caso, chutando as pedrinhas com raiva). Mais adiante, outros elementos econômicos da narrativa reforçarão e ampliarão este fracasso anunciado, como o encontro com um vizinho:

$\mathrm{Na}$ metade do percurso, ele encontrou outro homem descendo: um preto. Ele disse "oi" para o preto, seu conhecido. 0 preto vinha descendo e carregava uma caixa alongada, negra e de formato estranho. Contendo, provavelmente, um instrumento musical. 0 preto era músico e com certeza ia trabalhar, enquanto o outro homem já vinha voltando. Cansado e com raiva. 0 preto respondeu "oi" e continuou seu caminho, para baixo (SANT'ANNA, 1977, p. 59).

Já no primeiro período, aparece uma forma de endereçamento discriminatória de cor, resultante do encontro com o vizinho "preto". Na narrativa, este endereçamento remete a uma alteridade cultural longínqua, que demarca o "preto", assim como o "índio", como figuras raciais distintas das dos agentes sociais dominantes na formação da sociedade brasileira, indicando a noção ainda vigente de alteridade no tocante a figuras raciais distintas das do "branco" inclusive em grupos marginais ou periféricos, mesmo que tal noção não implique necessariamente racismo. $\mathrm{Na}$ economia narrativa, o encontro serve para indicar que o protagonista é "branco" ou, ao menos, de pele "clara", num sinal de que a condição social inferior não é exclusiva de uma ou outra raça, miscigenada ou não. Além disso, a narrativa enfatiza a insatisfação irracional do personagem, requalificando-o como "cansado e com raiva". Estilisticamente, esta requalificação serve como reforço e gradação, representando, por persistência ou insistência, o terrível impacto do bem lacunar sobre 0 ser do homem devido à ausência de fim para sua conduta. Outros elementos na narrativa que reforçarão seu fracasso triplo - nas três dimensões de referência, a espacial, a actancial e a temporal - surgem mais adiante no caminho do homem:

O homem subiu mais um pouco e logo avistou sua casa. Um barracão, um pouco melhorado. Com uma luz acesa e fraca lá dentro. A casa parecia uma caixa retan- 
gular, assim quase de noite. 0 homem apressou o passo, querendo chegar depressa.

Mas ele começou a ver, à margem do caminho, uns quatro ou cinco urubus devorando o cadáver de um cachorro. 0 homem viu e disfarçou, para que os urubus não percebessem que ele vira. 0 cachorro fedia e o homem pensou isto: "0 cachorro está fedendo pra cachorro". 0 homem riu do próprio pensamento e não tampou o nariz. Não existiam cheiros bons ou maus, apenas cheiros. 0 homem estava acostumado àqueles cheiros. Ele continuou olhando em frente, mas sabendo que os urubus levantaram a cabeça, desconfiados (SANT'ANNA, 1977, p. $60)$.

0 trecho citado inicia com uma variada semântica da residência que, em seu conjunto, reforça, especificando com mais detalhes, o fracasso espacial. Sua "casa" é, em verdade, um "barraco" (inferior), que, embora um pouco "melhorado" (dentro do possível permitido pela finitude presente), é "pequeno" (novamente inferior), lembrando, na penumbra, uma "caixa retangular" (sem ornamento). A dimensão actancial será também reiterada, graças ao episódio do cachorro morto e os urubus, que viabiliza a insensibilidade sensorial (habituado "àqueles cheiros", não tapa o nariz diante do cachorro morto), lingüística ("o cachorro está fedendo pra cachorro", ri-se ele) e social (nada faz diante das precárias condições de higiene do lugar) do homem. Em poucas linhas, a narrativa, assim, descreve um estado de coisas em que a negação do ser é naturalizada, o que dá motivo para evitar uma ação modificadora. Outro elemento que dará seqüência à iterativa negação e apagamento do ser representado é a atitude do homem diante dos urubus, esclarecida mais adiante:

O homem não olhava para os lados, porque tinha um plano.

Ele caminhou mais alguns passos silenciosos e, de repente, abaixou-se e pegou uma pedra grande no chão e atirou-a depressa e com toda a força nos urubus.

Os urubus bateram as asas afobadamente e saíram voando. 0 homem avistou algumas penas que flutuavam.

"Acertei!"

O homem viu três urubus que já iam longe. Mas um outro que voava com dificuldade, quase caindo. 0 homem acompanhou o urubu voando mais alguns metros, até pousar numa das casas. A sua própria casa, o homem verificou, sem acreditar em qualquer mau agouro. Ele achava que o urubu, na escuridão, parecia uma estátua de pássaro enfeitando a casa (SANT'ANNA, 1977, p. 60).

0 ataque aos urubus amplifica o episódio anterior das pedrinhas, levando-o a um nível mais profundo de agressividade. Senão, vejamos: como o trecho acima esclarece, o homem não é supersticioso, portanto, tanto se-lhe dá a presença ou não dos urubus, mesmo que em seu telhado; nenhum afeto o liga ao cachorro morto que os urubus atacam, então ele não tem motivo para odiar os urubus; 0 ataque não é motivado por repulsa, pois ele é qualificado como 
insensível ao cheiro fétido; não vai comer os urubus, portanto não os vê como presas; mesmo os prazeres da caça não o motivam, pois ele não vai atrás do urubu atingido, que, portanto, não tem valor de troféu. 0 que poderia restar? Uma boa pista neste sentido é, como disse acima, o episódio das pedrinhas. Naquele episódio, como no do ataque ao urubu, o sentido do gesto, como observei mais atrás, é a descompensação de um bem lacunar. No caso do urubu, este sentido, entretanto, se amplia: a ave que se alimenta de carne apodrecida, e que, portanto, vive à espreita de uma oportunidade fortuita, é um duplo animalizado do homem. Seu ataque, descompensador de sua raiva e impotência, portanto, adquire na narrativa o significado de uma "luta entre iguais", em que o homem, graças ao ferimento infligido na ave, pode reconhecer-se, ainda que por fugazes instantes, como "o melhor". A referência irônica ao final do trecho revela mais uma vez o uso estilístico a serviço de distanciar, pelo riso ou pelo humor macabro, o homem de uma situação desfavorável diante da qual sua razão emudece. A situação de perpétua privação do ser, todavia, não se altera quando ele chega ao seu destino:

Ele entrou na casa e não disse nada. Sentou-se junto à mesa e começou a tirar os sapatos. Adivinhando, pela disposição das coisas e pelos cheiros e sons, que a mulher cozinhava e eles comeriam de novo feijão com farinha e abóbora. E que o menino já dormia, porque não se escutava nenhum barulho de menino (SANT'ANNA, 1977, p. 60).

O parágrafo citado, embora curto, é um dos mais significativos da narrativa. Chamo particularmente a atenção para as denominações do narrador onisciente seletivo em relação aos três moradores da casa: ele evita deliberadamente os termos que significariam uma família - "pai" ou "marido"; "mãe" ou "esposa"; "filho" - em prol de termos biológicos gerais ("o homem"; "a mulher"; "o menino"), o que indica que os laços naquela residência são antes neutramente conviviais que familiares. A escolha vocabular denota, outra vez, o fracasso da dimensão passional do homem em seu próprio lar; este se torna, portanto, também naturalizado. Cabe acrescentar a rápida referência à mulher que cozinha, marcada pelo indicador freqüentativo "de novo feijão com farinha e abóbora", denotador também de carência, ou seja: falta de opções alimentares. Digno de nota é ainda o breve comentário sobre o menino, afirmado apenas pelo barulho, semanticamente, pois, um estorvo. 0 seguimento da cena ampliará, por sua vez, o fracasso interpessoal dos personagens adultos.

O homem continuou sentado e enfiou o dedo no nariz, enquanto a mulher, de camisola, saiu da cozinha com uma travessa de feijão e outra de abóbora. A farinha já estava na mesa e o homem olhou para a mulher e os pratos, sem dizer nada. Mas a mulher disse: "que era porcaria tirar meleca na mesa".

- Foda-se (SANT'ANNA, 1977, p. 61). 
0 trecho citado revelará uma divisão bem demarcada dos papéis do homem e da mulher, assim como de suas reações culturalmente típicas, numa relação pautada pela oposição: 0 homem sem higiene $X$ a mulher asseada; 0 homem desbocado X a mulher ranzinza; espaço do homem - sala X espaço da mulher - cozinha; a relação naturalizada do casal é vivida por ambos como confronto e distanciamento. Neste trecho é possível verificar o fracasso de ambos quanto ao eto discursivo. Como foi colocado na introdução, o eto discursivo é marcado pela pragmática, pela interação e pela sociabilização. No entanto, o casal não plurissematiza seu discurso: há somente uma queixa direta e incisiva por parte da mulher, a que se segue um xingamento forte por parte do homem. A mensagem não dita, porque não sabida de ambos, é que eles não se reconhecem um ao outro como pessoa plena, portanto, eles se inviabilizam para a intersubjetividade. Há uma lacuna essencial entre o homem e a mulher, cuja responsabilidade (também não reconhecida) é do casal, desafeito ao reencontro do eu/tu. No entanto, a cena entre os dois prossegue:

\footnotetext{
Então a mulher ficou em silêncio, por alguns minutos, ofendida. Depois ela não resistiu e perguntou se ele achava que a luz continuaria fraca daquele jeito. 0 homem apenas mexeu com os ombros e ela falou: - Vou perder o capítulo da novela.

0 homem comeu toda a comida do prato e depois tomou o cafezinho. Ela trouxe depressa o café, para poder limpar a mesa e ligar a televisão. Havia um aparelho muito velho, ali naquele mesmo cômodo (SANT'ANNA, 1977, p. 61).
}

0 trecho acima citado afirma implicitamente a troca de dizeres ríspidos anterior como rotineira para o casal. Após a efusão de raiva do homem e 0 amuamento silencioso da mulher, esta afinal procede a um apagamento da experiência e reinicia o contato. Desta situação, economicamente descrita, é possível inferir a aceitação tácita da rispidez como "regra do jogo" entre os dois. Ela ainda reduplica a raiva do homem, agora voltado contra a mulher para descompensar-se de si, que depois, um pouco mais quieto, termita seu jantar. A presença do aparelho de televisão, por seu lado, além de compor 0 realismo narrativo almejado, associa-se à uma instância cultural forte em nossa cultura, gradualmente dependente da mídia como válvula de escape, o que é denotado pela mulher, que serve rápido o café para ligar logo 0 aparelho. 0 caráter alienador da "paixão pela mídia" revela-se, destarte, com a programação ambicionada pela mulher, a popular novela:

\footnotetext{
Mas a luz estava muito fraca e as imagens eram apenas vultos indistintos e a muIher tinha de se contentar com as vozes. Uma voz de homem dizia: - Eu te amo, condessa; eu te amo de todo o coração.

- Você jura que nunca vai me abandonar, Alfredo; jura? - Juro.
} 
Depois houve alguns minutos de silêncio, com a música suave, de fundo, quando as duas imagens se aproximaram e deviam estar se beijando (SANT'ANNA, 1977, p. 61).

A linguagem estereotipada dos personagens da novela remete a um sério problema da cultura pós-moderna, que erigiu o entretenimento vulgar a terapia da realidade, a analgésico das agruras do cotidiano. A breve cena do casal estereotipado remete ao romantismo banal, com o agravante de apagar os problemas de uma cultura que há muito o ultrapassou. 0 passadismo cultural é, assim, um dos elementos de maior fascínio na programação midiática, pois conduz por instantes o espectador a um mundo menos complexo, com relações interpessoais intactas e marcadamente monoculturais ou culturalmente protecionistas, para vender a ilusão que não há outras culturas e, em conseqüência, não há culturas marginais. A programação da mídia torna-se, pois, de certa forma uma forma de descompensação também, mais branda que efusões de raiva como aquelas experimentadas pelo homem, mas não menos devastadora para o ser, por ser um estímulo contínuo à passividade e não à reflexão. A descrição lembra ainda, ironicamente, o melodrama em seu sentido etimológico original, de teatro musicado de pouca exigência artística. Adiante, a mulher prossegue assistindo ao desenrolar da situação imaginosa do casal novelesco:

A mulher estava de costas para o homem e ele teve certeza que ela chorava, emocionada. Mas ele mantinha os ouvidos atentos, porque julgava ouvir o baruIho do urubu no telhado. As vozes, porém, voltaram a falar e ele não podia certificar-se. $E$, de repente, houve batidas na porta.

- Corra, Alfredo: é papai.

- Abra a porta, Natália: eu sei que ele está aí.

Era uma voz de velho, enérgica, e a música tocava mais forte e solene (SANT'ANNA, 1977, p. 61).

Do trecho citado, destacam-se vários elementos culturais significativos. A pieguice da novela, dirigida primordialmente ao público feminino, descompensa a mulher da falta de significação essencial de sua relação com o homem. Este, por sua vez, entretém-se também de seu fracasso existencial ouvindo o barulho do urubu agonizante no telhado. Sua curiosidade é voltada para a manifestação da ave, que o barulho da novela o impede de certificar. A ave ferida, agonizando no telhado, representa, destarte, a reatualização de um fugaz momento de realização para o homem, sendo para ele um signo de sua força e do êxito de sua ação. A breve cena significa, no âmbito maior da narrativa, 0 isolamento essencial do homem e da mulher, em que cada um a seu modo busca, sem o saber, o ser perdido. Mas o homem, ansioso por ouvir o barulho da ave, retoma o contato assinalando-se outra vez pela grosseria e raiva: 
O homem levantou-se bruscamente, dirigindo-se para a janela.

- Por que você não desliga essa merda?

Mas logo depois ele riu, porque foi só falar aquilo e a luz se apagou de todo. 0 homem viu, pela janela, que as luzes da cidade inteira haviam se apagado. Ele oIhava lá para baixo, a cidade, não enxergando coisa alguma.

Como se a cidade tivesse desaparecido, ele pensou, mais calmo agora (SANT'ANNA, 1977, p. 62).

0 trecho citado conclui, de certa forma, o fracasso representado: insensível ao provável desapontamento da mulher, decorrente da falta súbita de luz, o homem ri. Pela janela, ele percebe que a falta de luz é geral; toda a cidade, desta forma, compartilha agora uma mesma situação de privação. A ocasional escuridão torna-se, entretanto, motivo de júbilo para o homem. Graças a ela, a população, marginal ou não, se iguala pela carência, o que dá ao homem, por já ter-se habituado a ela, a vantagem proveniente do hábito adquirido pelo longo convívio com o fracasso em três dimensões. Aqui esclarece-se a falência ética do personagem, em consonância com as estruturas modais e aspectuais viabilizadas. No que se refere às primeiras, ele é, em realidade, nulo, pois não é nem faz. Sua atualidade é projetada somente para a agressão a tudo que seIhe aparece no plano fenomenal, seja contra objetos, animais ou pessoas, numa busca desesperada de afirmar poder. Finalmente, sua virtualidade é, tal como sua realidade, nula, pois ele não exerce nem cogita exercer nenhum ato transcendente. Em termos experienciais, na realidade e na virtualidade ele nega o ser; por outro lado, ele complementarmente, na atualidade, afirma 0 não-ser. Sua falência deriva, por conseguinte, de uma complementaridade das instâncias tridimensionais do discurso que ele rejeita para não se realizar como pessoa ética. Por outro lado, no que se refere às segundas, a narrativa representa uma ação freqüentativa, que se repete todos os dias de não-ser, cortada por ocasionais intervenções pontuais (o urubu, a falta de luz), que o homem aproveita para descompensar-se, como foi dito acima, pela agressão. Em consonância com isto, ele, "mais calmo agora", com a generalização da carência por toda a comunidade fenomenalmente a seu alcance, deita-se para dormir:

O homem começou a tirar a camisa ali mesmo e foi andando, no escuro, para o quarto. Com o silêncio, ele ouviu nitidamente o urubu se debatendo no telhado.

0 homem se atirou na cama e sentiu que dormiria logo. Mas ficou escutando mais um pouco o urubu. - Eu te acertei, bicho - ele disse baixinho (SANT'ANNA, 1977, p. 62).

Em conclusão, o dia se encerra com a afirmação agressiva de sua força; em verdade, uma forma desesperada de afirmação do não-ser pela crueldade imotivada. A tranqüilidade com que ele encerra seu dia, por tudo que foi visto antes, representa na narrativa o conforto fugaz derivado de uma falsa solução. 
Cabe aqui reforçar o aspecto pontual destas pseudo-soluções, ocasionais, que ele deliberadamente não busca para transcender-se, mas para negar-se mais ainda como pessoa ética. Lembrando também o aspecto freqüentativo representado na narrativa, o encerramento do dia do homem é, em verdade, melancólico, porque fadado a se repetir sem que ele reaja em prol de si, e, para piorar, sem garantia de urubus no dia seguinte. Conclui desta forma a narrativa com a representação plena de uma cultura marginal, não apenas porque pobre ou carente, mas sobretudo porque privada voluntariamente de forças para lutar por si, por seu valor, pelo resgate vital de seu discurso; enfim, por sua ética.

\section{CONCLUSÃO}

Do que foi exposto até aqui, permito-me concluir que o conto "Sombras", já a partir das escolhas textuais promovidas pelo autor para perfazer sua encenação, representa uma ética falhada brilhantemente narrada, pois assinala com economia de recursos os princípios fundamentais do ser como fracassados, o que aumenta o drama do protagonista, alienado até deste (isto é: do drama) mesmo. A realização narrativa audaciosamente promove um narradoroutro do homem, num exercício de captação realista de um drama anônimo, tristemente vivido por parcela significativa de pessoas em nossa cultura pósmoderna, que busca o distanciamento e 0 apagamento de nós mesmos. Ao denunciar este apagamento, o autor significa, por sua vez, sua obra, alertandonos para a vã promessa do simulacro que cotidianamente nos é dada - e sem a garantia confortadora dos urubus...

\section{REFERÊNCIAS}

ABBAGNANO, Nicola. Dicionário de filosofia. Trad. Alfredo Bosi e Ivone Castilho Benedetti. 4. ed. São Paulo: Martins Fontes, 2000.

CHARAUDEAU, Patrick. Discurso das mídias. Trad. Ângela Corrêa. 1. ed.1. reimpr. São Paulo: Contexto, 2007.

FONTANILLE, Jacques. Semiótica do discurso. Trad. Jean Cristtus Portela. São Paulo: Contexto, 2007.

MAINGUENEAU, Dominique. A propósito do ethos. Trad. Luciana Salgado. In: MOTTA, Ana Raquel; SALGADO, Luciana. (Org.). Ethos discursivo. São Paulo: Contexto, 2008, p. 11-29.

MOTTA, Ana Raquel; SALGADO, Luciana. (Org.). Ethos discursivo. São Paulo: Contexto, 2008.

NÖTH, Winfried. A semiótica no século XX. 3. ed. São Paulo: Annablume, 2005.

SANT'ANNA, Sérgio. Sombras. In: Idem. Notas de Manfredo Rangel, repórter (a respeito de Kramer). 2. ed. Rio de Janeiro: Civ. Brasileira, 1977. 